\title{
Gestão dos efluentes líquidos das indústrias de farinha de mandioca de Araruna - PR
}

\author{
Amalia Maria Goldberg Godoy, $D r$. \\ Professora Adjunto do Departamento de Economia da Universidade Estadual de Maringá - Paraná - Brasil e \\ doutoranda do PROCAM/USP \\ Avenida Colombo, 5790 \\ 87.020-900 - Maringá - Paraná \\ fone: 044- 261-4305 \\ fax: 044-261-4488 \\ amggodoy@uem.bre gold@wnet.com.br \\ Ricardo de Jesus Carvalho dos Santos, M.Sc. \\ Professor Assistente do Departamento de Economia da Universidade Estadual do Paraná - Unespar/Campo Mourão.

\begin{abstract}
Este artigo tem como objetivos apresentar se e como as pequenas e grandes agroindústrias da mandioca, em Araruna no Paraná, se adequam à legislação ambiental no tratamento dos efluentes gerados no processo de produção. As agroindústrias foram classificadas em agroindústrias I (pequenas) e agroindústrias II (grandes). Pesquisando a legislação atual e pertinente ao setor foi medido o lançamento dos efluentes nos corpos receptores. Como resultado verificou-se que tanto a agroindústria I quanto a agroindústria II obedecem à legislação ambiental. No entanto, enquanto as maiores têm facilidades em se adequarem, as pequenas além de terem maiores dificuldades, possuem maiores custos em seu controle o que constitui em mais uma desvantagem para as micros e pequenas empresas.
\end{abstract}

Palavras-chaves: agroindústria; mandioca; efluentes líquidos; meio ambiente.

This article has as objective to discover if and how the small and big agricultural industries of the cassava, in Araruna - Paraná, are adapted to the environmental legislation in the treatment of the flowing out generated in the production process. The agricultural industries was classified in agricultural industrie I (the small) and agricultural industrie II (the big). Researching the pertinent legislation, the flowing out was measured in the lacks of reception. As result both agricultural industrie I and agricultural industrie II obeys the environmental legislation. However, while the largest ones have means in they adapt, the small ones besides they have larger difficulties, they possess larger costs in its control that constitutes in more a disadvantage for small companies.

Keywords: agricultural industrie; cassava; liquid flowing out; environment.

\section{Introdução: uma visão da agroindústria da mandioca e as pressões ambientalistas}

\subsection{A Agroindústria da mandioca}

O cultivo da mandioca é antigo no Brasil e, segundo Conceição (1979), era conhecido pelos nativos, antes mesmo do descobrimento da América. Até a década de 1970, preponderantemente, a mandioca era utilizada de forma in natura para alimentação dos animais ou, por meio de simples processamentos, chegava à mesa dos brasileiros cozida ou sob a forma de farinha. Nessa fase, a indústria era de baixa tecnologia.
Na década de 70 do século XX, no Brasil, houve a disseminação do novo modelo agrícola, conhecido como Revolução Verde, surgem as agroindústrias da mandioca, agora mais intensivas em capital, que passam a produzir uma série de outros produtos tais como: fécula, sagu, farinhas brancas finas e grossas e vários tipos de farofa temperada.

No caso de Araruna, encontram-se os dois sistemas de produção. Detecta-se a presença de grandes agroindústrias da mandioca que mantêm-se funcionando durante o ano inteiro, através dos contratos estabelecidos com os micro, pequenos e médios produtores (da região, do estado e de outros estados) e, também, de pequenas farinheiras que 
vendem seu produto e/ou entregam o produto semielaborado à grande empresa.

Com relação à questão ambiental, nos anos 19701980, ocorre uma percepção maior dos impactos ambientais e ampliam-se as discussões, inclusive em nível internacional.

A maior pressão da sociedade com relação à preocupação com os impactos ambientais e a crescente busca de alternativas de desenvolvimento menos predatórias levaram a mudanças de comportamentos das empresas. Algumas empresas passaram a planejar seus investimentos em tecnologias menos poluentes do solo e da água e menos predatórias das florestas e biodiversidade. Estas passam a buscar mecanismos de ação para incrementar o aproveitamento de resíduos, evitando assim a exploração de novos recursos naturais e o acúmulo de materiais desperdiçados. Por outro lado, a grande maioria das outras empresas passa a se preocupar com os efluentes líquidos e gasosos e resíduos das suas empresas devido às multas decorrentes da poluição em suas diversas formas.

A agroindústria de mandioca, também, necessitou se adaptar a esse novo cenário. Assim, a partir dos anos 90, passa a ser implementada uma Legislação Ambiental voltada às mais diversas atividades econômicas, inclusive as farinheiras.

Surge a questão: como essas farinheiras se adaptam às novas necessidades legais? Elas cumprem, independentemente do tamanho, a legislação ambiental em curso, especificamente no tratamento de seus efluentes gerados na fabricação da farinha de mandioca?
Para responder a questão apresenta-se, primeiramente o processo de produção de uma indústria de farinha.

\section{0 processo de industrialização da farinha de mandioca}

Os produtos derivados da mandioca, segundo ABAM - Associação Brasileira dos Produtores de Amido de Mandioca - (1999:16), que também congrega fabricantes de máquinas, pesquisadores e produtores de farinha, são: a) amiláceos: composto por amido (fécula), polvilho azedo, sagu, tapioca, modificados e b) Farináceos: constituido por farinha branca (fina e grossa), farinha torrada (amarela), farinha biju (flocos), farofas.

A Figura 1 mostra o fluxograma do processo de produção dos farináceos e os pontos de geração dos efluentes.

Após entrevistas com vários empresários e visita às empresas, pode-se dizer que o pequeno agricultor vende o produto in natura para a agroindústria e acerta o dia da entrega. A mandioca é um produto perecível e após a colheita tem que ser industrializada em 24 horas, no máximo.

Os trabalhos de colheita, transporte e industrialização ocorrem de forma sincronizada. Entende-se como Colheita - a operação que envolve o arranque do solo que pode ser feito de forma manual ou mecânica e, por Transporte - a destinação da matéria-prima arrancada do seu local de cultivo para a agroindústria, onde será transformada. Na seqüência apresentamos as operações de processamento na agroindústria: 


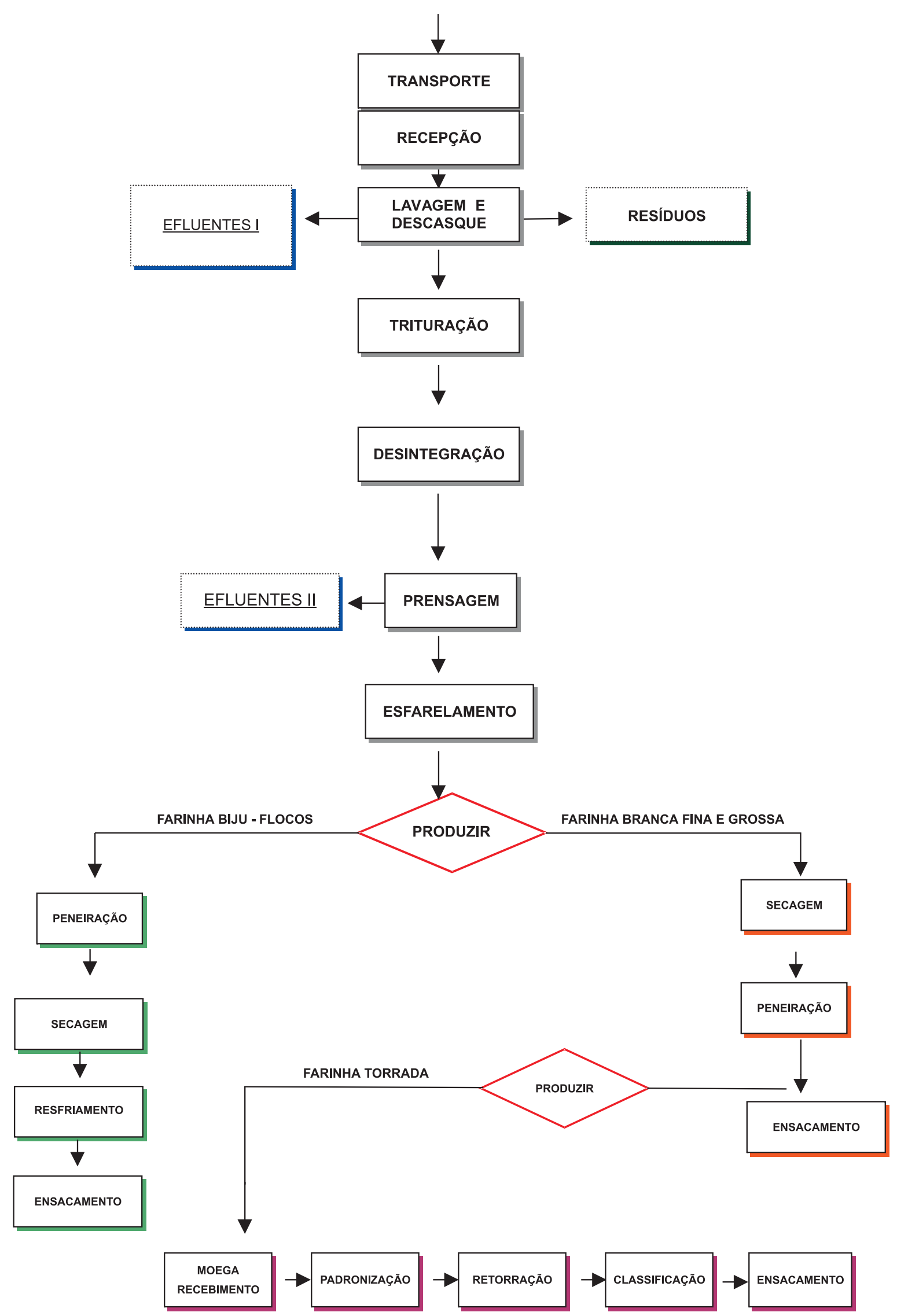

Figura 1- Apresentação do Flụxograma da Indústria Farinheira Fonte: Terra Engenharia Ambiental (1997), modificado pelo autor 
a) Recepção - na recepção faz-se a identificação quanto à origem e a pesagem para o controle da matériaprima. Em seguida, a mandioca in natura é encaminhada para o depósito e, na sequiência, transportada por correia transportadora para o lavador;

b) lavagem e descasque - este processo visa a retirada de areia e terra facilitando o descasque que é feito simultaneamente. Para tal atividade é necessária grande quantidade de água, que é carreada para lagoas de decantação e, na maioria dos casos, é posteriormente lançada nos rios. Nessa fase é gerado o Efluente I, composto de materiais sedimentáveis e resíduos (cascas);

c) seleção - após estarem descascadas e livres de impurezas, as raízes passam por uma correia transportadora, da qual são retiradas, manualmente, aquelas consideradas impróprias para a industrialização;

d) trituração e desintegração (moagem) - a moagem objetiva diminuir o tamanho das raízes, para que se possa obter uma massa mais uniforme;

e) transporte - é o meio para o deslocamento da massa moída até a prensa;

f) prensagem - a massa moída, nessa fase, ainda é muito pesada e rica em água, que necessita ser extraída para que a secagem seja mais rápida e uniforme. A massa é envolvida em tela de pequena granulometria que permite somente a passagem da água. Esta água é chamada de manipueira ou Efluente II;

g) esfarelamento (moagem) - a massa, após a prensagem, deve ser moída para adquirir uma granulometria que atenda aos requisitos de produção especificados para o produto desejado, facilitando a secagem;

h) secagem - a secagem consiste em expor o material moído ao calor. Este processo pode ser feito por meio de fogo direto, em tachos industriais ou por meio de vapor quente;

i) classificação - a classificação é uma operação muito importante no processo porque possibilita atender as diferentes demandas do mercado. Essa é feita por peneiras com diferentes granulometrias;

j) padronização e ensacamento - a padronização é feita pela moagem do produto classificado para adquirir a mesma granulometria e aparência física.
Em seguida é armazenada em sacos com diferentes pesos ou a granel.

Ressalta-se que, independentemente do tamanho da empresa, as fases do processo de produção obedecem à mesma sequiência e que tanto as agroindústrias pequenas quanto as grandes possuem processo igual ao descrito. Entretanto, as agroindústrias pequenas geralmente só fabricam farinha branca, que possui mercado específico e/ou fornecem a farinha branca para as grandes empresas. Portanto, as grandes empresas adquirem tanto a matéria-prima in natura quanto produtos semi-elaborados como a farinha branca das pequenas farinheiras.

Com relação aos efluentes gerados, pode-se apontar que a água originada da lavagem da matéria-prima que no meio técnico convencionou-se chamar de EFLUENTE I, nada mais é do que os resíduos oriundos da lavagem da raiz, cujas águas ficam repletas de pequenas cascas, partículas, areia e terra, devendo ser acondicionadas segundo as normas legais (Resolução CONAMA 20/ 1986). Essas cascas são ricas em nutrientes e podem servir como ração animal e adubação. Quanto às lagoas de decantação, essas servem para reter as casquinhas e outras partículas que tenham passado pelos sistemas.

Por meio da decantação reduzem-se os lançamentos de materiais sedimentáveis nos corpos receptores, o que diminui o impacto ambiental causado pelos despejos, pois quanto mais matéria orgânica for lançada num corpo hídrico, maior será a necessidade de oxigênio para decompô-la e estabilizar as condições físico-químicas do efluente.

Portanto, o efluente destina-se à lagoa anaeróbia e em seguida para as lagoas facultativas onde se completa a decantação e em seguida para os corpos receptores. É rico em matéria orgânica e partículas. As casquinhas podem ser destinadas à adubação e/ ou alimentação animal.

Os EFLUENTES II são os resíduos líquidos provenientes da prensagem da raiz. As destinações dadas, geralmente, são a fertirrigação direta nas lavouras e pastagens, ou acondicionamento total em lagoa para decantação e evaporação.

É importante salientar que esse efluente é muito danoso à vida aquática, causando alto impacto se lançado diretamente nos corpos receptores (rios e/ ou lagos). Levam consigo grande volume de água rica em cianeto esse efluente é mais conhecido nos meios técnicos como água de manipueira e é portanto, impróprio para consumo humano, animal e despejos em cursos d'água. 


\section{Metodologia}

Como o objetivo do trabalho é averiguar se e como as empresas de pequeno e grande portes adeqüam-se às exigências ambientais, as coletas de dados foram diferenciadas: a primeira foi desenvolvida de maneira a acompanhar o tratamento dos efluentes e a segunda refere-se às características das empresas pesquisadas. Apresentam-se as duas metodologias separadamente.

\subsection{A coleta e análise dos efluentes das agroindústrias}

O município de Araruna conta com 12 agroindustriais de farinha, com graus distintos de tecnologia. Para averiguar a adequação do tratamento dos efluentes foram selecionadas duas empresas de Araruna: uma pequena designada de Agroindústria I e uma grande farinheira chamada de Agroindústria II.

O estudo se desdobrou em seis etapas: 1) Reconhecimento das instalações industriais e sistemas de tratamento de efluentes; 2) Reconhecimento dos locais de destinação dos efluentes; 3) Entrevistas com os diversos atores sociais; 4) Coletas de amostras dos efluentes e dos corpos receptores; 5) Análise química das amostras; 6) Interpretação e discussão dos dados.

As coletas das amostras de água foram feitas em três pontos: à montante da agroindústria (cerca de 50 metros); na lagoa de decantação próxima à agroindustria (cerca de $100 \mathrm{~m}$ ) e no ponto de lançamento dos efluentes, ou seja, nos rios. Cada coleta, portanto, compõe-se de três amostras para a Agroindústria I e três para aAagroindústria II. Registra-se que quando não havia lançamento no rio, optou-se pela coleta da amostra do efluente II na última lagoa facultativa. O lançamento final é nos rios: água do Fifina ou rio Guaraipó, córrego Guaritinga ou Gravitinha, ambos afluentes do rio Ligeiro, que, por sua vez é afluente do rio Ivaí.

Após a coleta, procedia-se a identificação, etiquetagem.

As amostras eram acondicionadas em galões especiais de 5 litros cada, os quais, por sua vez, eram colocados em caixas térmicas que vinham esterilizadas do laboratório. O despacho, por transportadora, para o laboratório do Instituto Ambiental do Paraná-IAP, ocorria no dia seguinte. As amostras, portanto, eram coletadas no dia anterior à data de entrada das mesmas no laboratório.

As coletas foram realizadas no período de outubro de 2000 até junho de 2001, uma por mês, o que totaliza nove coletas. A coleta realizada no mês de outubro/2000 recebeu o número 1 , a do mês de novembro/2000 recebeu o número 2 e assim por diante até junho/2001, a qual recebeu o número 9. Coletou-se, no total, 54 amostras.

Os parâmetros físico-químicos analisados em virtude da disponibilidade do laboratório do IAP e segundo SEMA/IAP (1998) a e b, onde constam o Decreto Estadual $n^{\circ} 857 / 79$ e a lei estadual $n^{\circ} 7109 / 79$, foram: DBO; DQO; pH, Matéria Sedimentável e a temperatura e consumo de água.

pH - Potencial Hidrogeniônico, representa a concentração de íons de hidrogênio que indica o caráter ácido, neutro ou alcalino da água. Para a agroindústria da mandioca, o $\mathrm{pH}$ deve estar entre 5 e 9;

DBO - Demanda Bioquímica do Oxigênio - retrata a quantidade de oxigênio requerida para estabilizar, através de processos bioquímicos, a matéria orgânica carbonácea. É uma indicação indireta, portanto, do carbono orgânico biodegradável (SPERLING, 1996:66). O DBO tratado deve ser de até 100mg/l;

DQO - Demanda Química de Oxigênio - mede o consumo de oxigênio ocorrido durante a oxidação química da matéria orgânica. $O$ valor obtido é uma indicação indireta do teor de matéria orgânica presente (SPERLING, 1996:69); e do volume e a temperatura. O DQO tratado deve ser de até $250 \mathrm{mg} / 1$;

O Consumo de Água deve estar entre 2,0 e 2,5 $\mathrm{m}^{3} /$ tonelada de mandioca processada;

A Temperatura deve ser menor do que $40^{\circ} \mathrm{C}$;

Os Materiais Sedimentáveis, que são partículas presentes no meio líquido que vão consumir oxigênio para decompor-se e, com isso, concorrer com os outros seres vivos por este nutriente (CEREDA, 1994). Este deve ser de até $1 \mathrm{ml} /$ litro.

A metodologia usada em laboratório é Standard Methods proposta por Franson (1998), sendo para o DBO incubação $20^{\circ} \mathrm{C} \mathrm{em} 5$ dias $\left(\mathrm{DBO}_{5}\right)$ sem a presença da luz. Para a medição do DQO o método utilizado é o do refluxo aberto. Para a análise de Material Sedimentável utiliza-se o teste de 1 hora, em cone imhoff. $\mathrm{O}$ pH foi medido através do potenciômetro.

É muito importante ressaltar que a agroindústria I, durante os meses de monitoramento, não fez nenhum despejo no rio, pois, a capacidade das lagoas de tratamento das águas de lavagem era superior ao volume de matéria-prima industrializada.

A agroindústria II, com maior porte e maior volume de matéria-prima industrializada, fez apenas um lança- 
mento no rio. Na realidade durante o período analisado, houve uma única coleta no rio. As lagoas de decantação e facultativas foram suficientes para absorver os efluentes gerados no processo produtivo das duas agroindústrias.

A pesquisa realizada levando em conta, apenas, $\mathrm{DBO}$, DQO, pH, Matéria Sedimentável e Temperatura, na prática, se apresenta como instrumento mínimo que dá uma visão de como as agroindústrias estão gerenciando os seus efluentes.

Pode-se apontar, de um lado, que alguns parâmetros legais estipulados estão ultrapassados, tais os limites para o uso do DDT e do BHC, os quais são proibidos em todo o território brasileiro. Por outro lado, existem outros produtos com princípios ativos muito poderosos, que ainda não foram normatizados pela legislação, como a Bentazona. Enfim, quer se chamar a atenção de que não há condições de se emitir pareceres mais abrangentes visto que as bases técnicas e legais são muito restritas.

\subsection{Levantamento de dados das agroindústrias}

Para o levantamento das condições técnicas das farinheiras, foi elaborado um questionário para os empresários e outro para os funcionários.

O questionário aplicado aos empresários tinha como objetivo averiguar tanto as características dos empresários quanto das empresas. Com relação às empresas, as questões tocavam, particularmente, na utilização da água, tratamento de efluentes, tipo de resíduos gerados, entre outros. Através do mesmo, teve-se a possibilidade de comparar se as condições tecnológicas da grande empresa são diferentes da pequena empresa.

A aplicação do questionário ocorreu entre os meses de outubro de 2000 a junho de 2001.

Os questionários foram aplicados em 9 das 12 agroindústrias do município de Araruna. Essas 9 organizações representavam $75 \%$ das agroindústrias e empregavam 218 funcionários diretos e indiretos.
O $1^{\circ}$ grupo estudado constituiu-se de 7 pequenas empresas que possuem baixa tecnologia industrial, as quais chamou-se de agroindústria - I. Elas possuíam um total de 86 funcionários.

O $2^{\circ}$ grupo, composto por empresas com tecnologia mais intensiva em capital, é representado por duas empresas denominadas de agroindústrias II. Nesse segmento há um total de 132 funcionários.

As entrevistas foram sistematizadas no programa Excel e a apresentação de resultados foi elaborada através de gráficos e tabelas.

\section{Apresentação de dados e análise}

Os dados e as análises a serem abordados neste item são: a) resultados laboratoriais das análises de águas; b) características tecnológicas das empresas estudadas.

A seguir são apresentados os resultados laboratoriais das análises de águas coletadas junto às agroindústrias I (de pequeno porte) e agroindústria II (de grande porte).

\subsection{Resultados laboratoriais dos Efluentes das agroindústrias}

Na agroindústria I verifica-se que o sistema de tratamento é composto por uma lagoa anaeróbica e duas lagoas facultativas. Em função do volume de matériaprima trabalhada, inferior à capacidade das lagoas no período de coleta de dados, verificou-se que não houve nenhum lançamento de efluente no rio.

Ressalta-se, também, a relevância do fato de que, durante o período das coletas 5, 6, 7 e 8, essas agroindústrias trabalharam com um volume menor de matéria-prima do que os períodos 1, 2, 3, 4 e 9 (em virtude dos baixos preços), o que inviabilizou a coleta de amostras do efluente nas lagoas facultativas.

Na agroindústria II, por sua vez, verifica-se que o sistema de tratamento é composto por uma lagoa anaeróbica e quatro lagoas facultativas. Em função desse número de lagoas e de um bom sistema de retiradas de cascas e sedimentos durante o processamento da mandioca tem-se que menores quantidades de partículas são carreadas.

Com relação ao pH, apresenta-se o gráfico da Figura 2. 


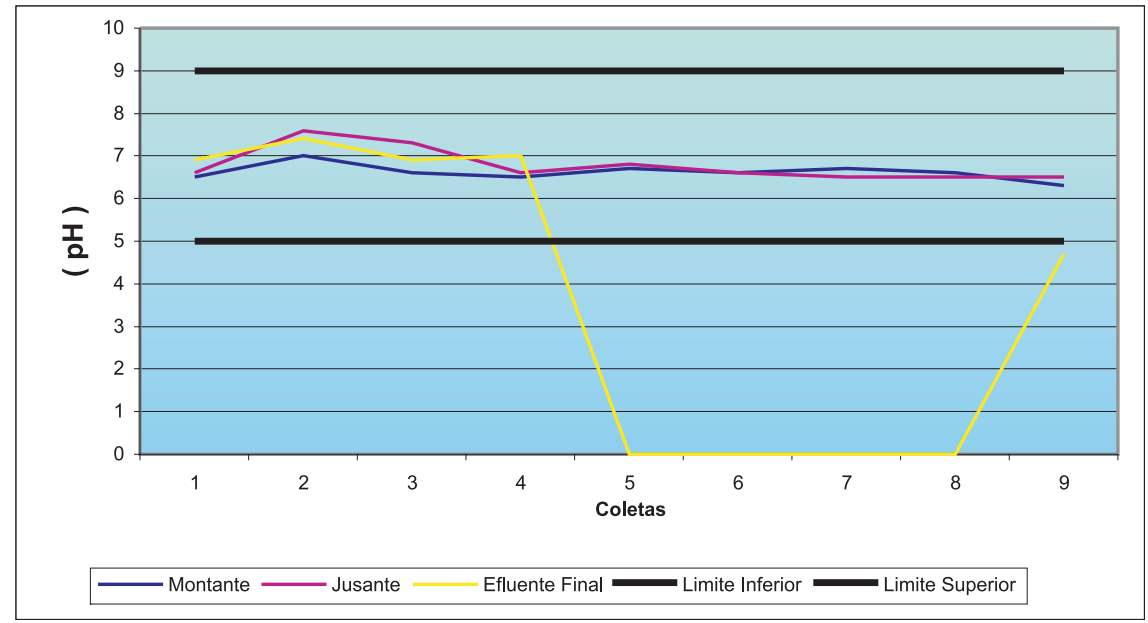

Figura 2 - Variação do pH - Agroindústria I - Período 1 a 9

Fonte: Pesquisa de campo

Verificou-se, na agroindústria I, que as amostras coletadas à montante, à jusante e na lagoa de decantação estão dentro do padrão estipulado pela legislação (pH 5 a 9). Os resultados laboratoriais apresentaram uma variação de 6,3 até 8,3, ou seja, a amplitude é de 2,0 pontos. Essa oscilação é muito superior à variação da agroindústria II, indicando uma maior instabilidade nas águas da lagoa de decantação, o que surpreende, visto que não houve lançamento de efluente neste período, e, portanto, tal alteração pode ter sido provocada por carreamento pelas águas das chuvas de solo agricultável com resíduos químicos, dias antes da realização da coleta.

Com referência aos índices zero das coletas 5, 6, 7 e 8, observa-se que em virtude do baixo preço da mandioca $(\mathrm{R} \$ 34,00$ por tonelada), a agroindústria I utilizou cerca de $30 \%$ de sua capacidade resultando em baixa produção nesse período, as lagoas ficaram ociosas em torno de $70 \%$ de sua capacidade, não ocorrendo assim, nenhum lançamento. Na prática, não houve condições de se coletar os dados no efluente final, somente a montante das instalações industriais.

A Figura 3 apresenta as variações de $\mathrm{pH}$ para a grande empresa.

Verificou-se que as amostras coletadas à montante, à jusante e nas lagoas de decantação, também, estavam dentro do padrão estipulado pela legislação ( $\mathrm{pH} 5$ a 9). Os resultados laboratoriais apresentaram uma variação de 6,5 até 7,2 , ou seja, uma amplitude de 0,7 pontos, portanto, bem menor do a agroindustria I, indicando maior controle sobre o $\mathrm{pH}$ do efluente.

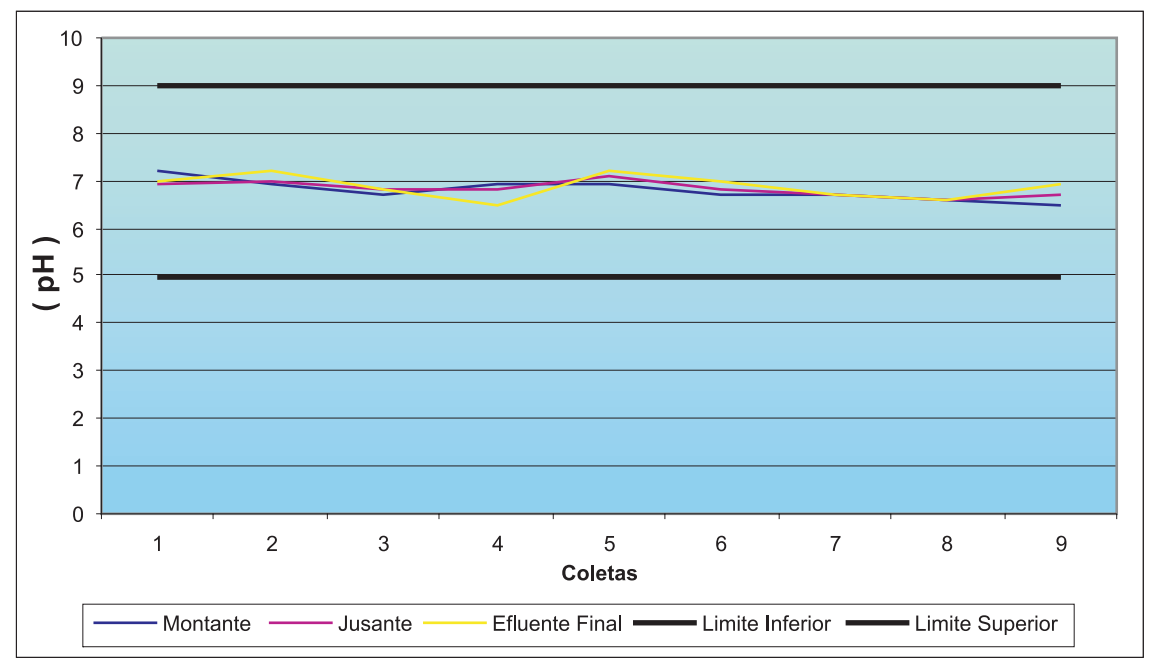

Figura 3 - Potencial Hidrogeniônico $(\mathrm{pH})$ - Agroindústria II

Fonte: Pesquisa de campo 


\section{Produto \& Produção, vol. 7, n. 3, p. 37-49, out. 2004}

A Figura 4 apresenta os resultados do material sedimentável da agroindústria I.

Quanto aos materiais sedimentáveis, verifica-se que tanto à montante quanto à jusante da agroindústria I, os volumes encontrados na grande maioria da amostras se apresentam menores que $1 \mathrm{ml} / 1$, sendo que o permiti- do por lei é de $1 \mathrm{ml} / \mathrm{l}$. Constata-se que mesmo na lagoa de decantação, em todas as coletas, ele está abaixo do padrão permitido, no entanto, a oscilação é alta nos meses 1 a 4 indicando dificuldades em estabelecer um padrão de geração de material sedimentável.

A Figura 5 apresenta a análise para a agroindústria II.

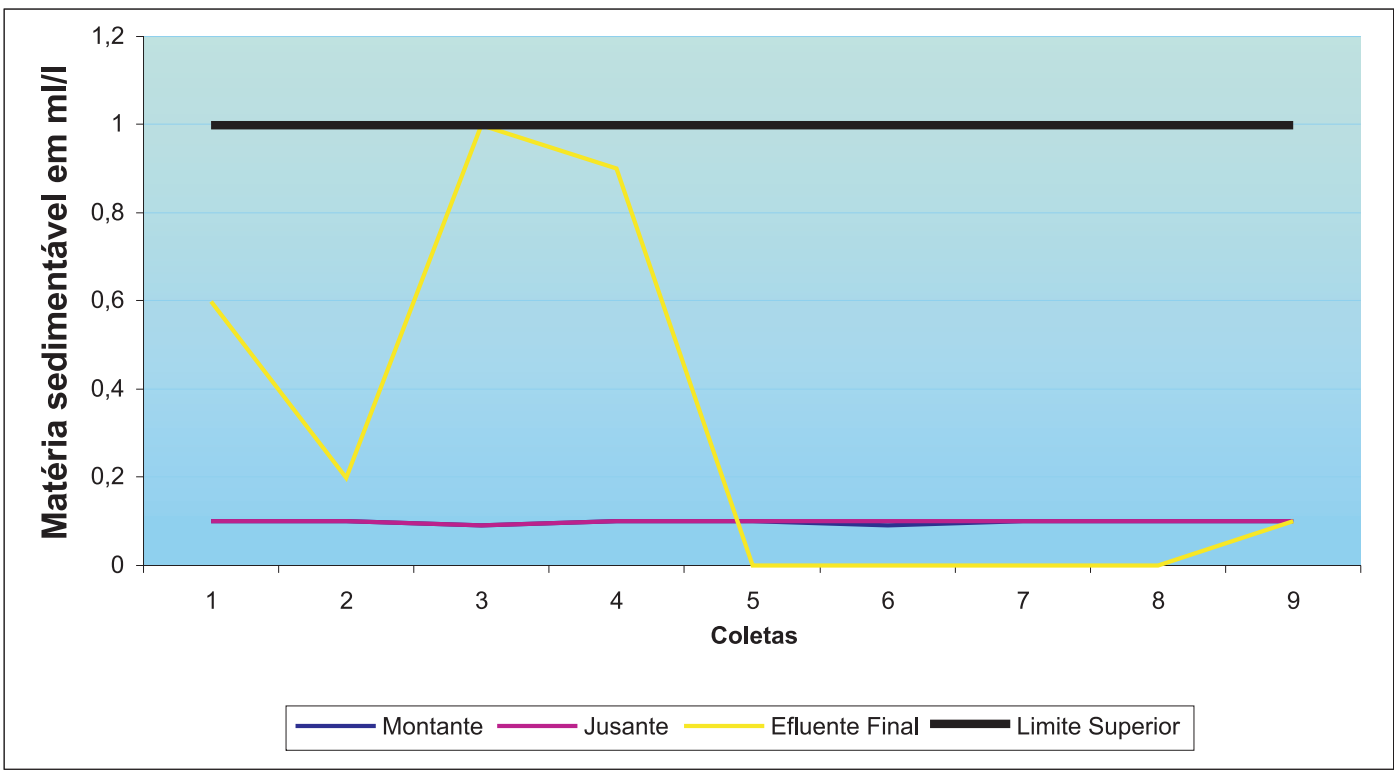

Figura 4 - Matéria Sedimentável Agroindústria I

Fonte: Pesquisa de Campo

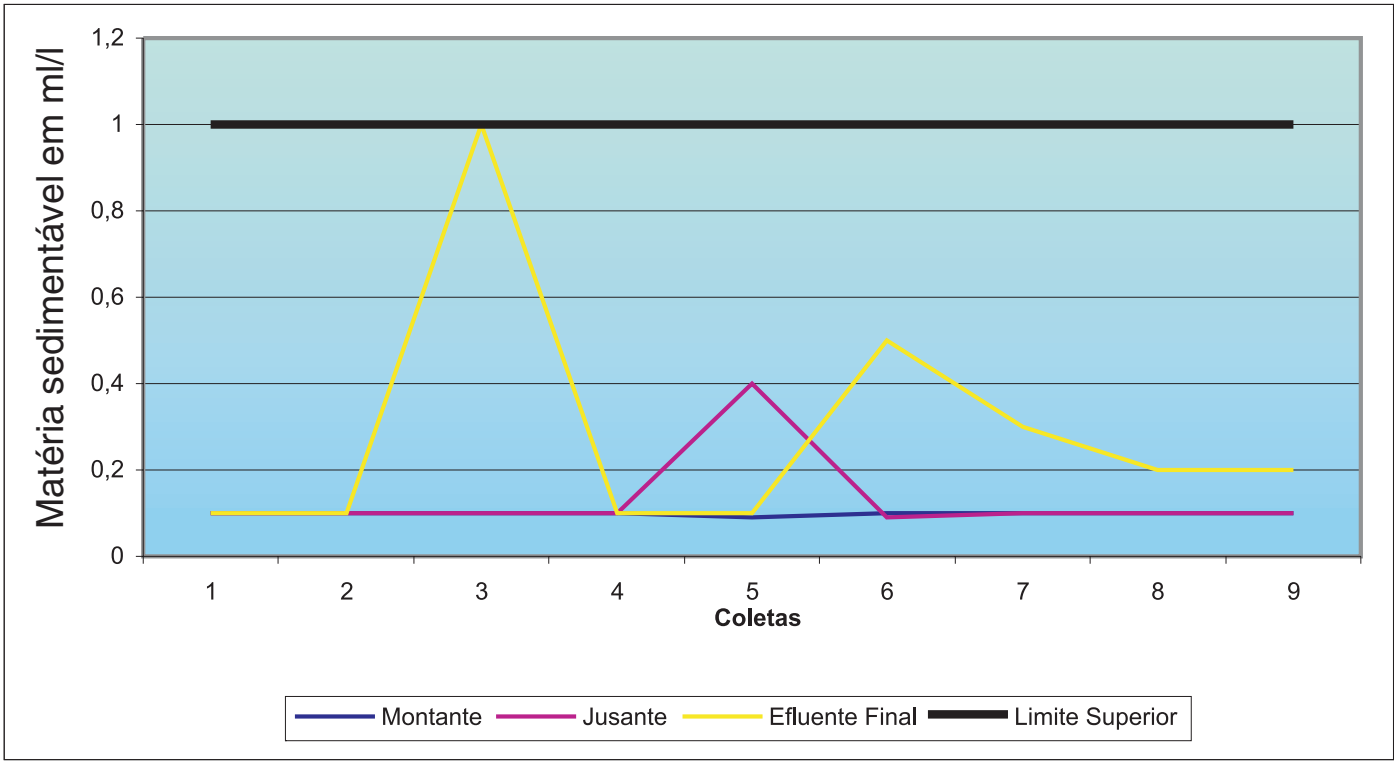

Figura 5 - Matéria Sedimentável - Agroindústria II

Fonte: Pesquisa de campo 
Na agroindústria II, verifica-se que, tanto à montante quanto à jusante, os volumes encontrados na grande maioria das amostras são menores do que $0,1 \mathrm{ml} / 1$, ou seja, estão dentro do permitido por lei que é de $1 \mathrm{ml} / \mathrm{l}$ de matéria sedimentável. Verificou-se que mesmo no ultimo ponto de coleta (efluente final) o valor encontrado está abaixo do padrão em mais de $88 \%$ das amostras. Somente numa amostra (de número 3), a concentração foi superior, mas, mesmo assim, não alterou as características da água do corpo receptor.

Observa-se, também, que há picos na análise do efluente final, tanto na agroindústria I quanto na agroindústria II, o que indica que o sistema de controle não alcançou um padrão. O empresário, nesse caso, precisa verificar se os instrumentos de retirada de casca e impurezas não estão com defeitos, pois, na coleta para análise dos mesmos eles oscilam muito. Isso pode extrapolar o parâmetro permitido e causar prejuízos ambientais, elevando assim o nível de sedimento nas águas dos rios, com isso, eleva-se o consumo de oxigênio para estabilizar a massa d'água prejudicando a fauna existente.

\section{Com relação ao indicador DBO, a agroindústria I} apresentou um DBO médio de 3 a 10 vezes maior do que os verificados na agroindústria II, nas coletas 1, 2, 3 e 9 (ficaram prejudicados os períodos 5, 6, 7 e 8 devido a baixa produção). Isso significa dizer que, na média, o indicador DBO da agroindústria II é 3 a 10 vezes menor do que os verificados na agroindústria I e isto evidencia uma melhor tecnologia no tratamento do mesmo e no processo. Observa-se também que as médias aritméticas durante o período das coletas mantêm uma certa estabilidade, sendo que a menor observação é de 6,33 mg/l e a maior é de 30,99 mg/l (DBO).

Com relação aos resultados da DBO da agroindústria I e II, constata-se que as águas à jusante estão dentro do padrão legal estabelecido. Os resultados encontrados à jusante são iguais ou muito próximos dos encontrados à montante da agroindústria, significando que o volume da carga poluidora está baixo, o que na prática significa dizer que não consegue alterar significativamente as características da água no ponto de lançamento. Embora sem originar problemas, encontrou-se na ultima lagoa de decantação diversos períodos em que se ultrapassou os limites legais, mostrando que o empresário tem maior custo com o tratamento do efluente para que o mesmo se enquadre aos parâmetros legais.

Sem entrar em todos os indicadores analisados das amostras coletadas, pode-se afirmar que a agroindústria I, a de menor porte, foi a que apresentou maior freqüência de extrapolação dos indicadores nas lagoas de decantação, ou seja, ultrapassou a norma legal para material sedimentável, DBO e DQO.
A agroindústria II, por sua vez, ultrapassou o parâmetro legal somente em material sedimentável nas lagoas de decantação.

As agroindústrias I e II, contudo, não ultrapassaram os padrões legais nos rios, durante a pesquisa. No entanto, salienta-se que as lagoas de decantação da agroindústria I são muito superiores à geração dos efluentes em função do pouco volume de matériaprima trabalhada no ano de 2001. Nesse contexto, os resultados da agroindústria I poderiam ser piores.

Os resultados encontrados de pH; DBO; DQO; Materiais Sedimentáveis e Temperatura estiveram todo o tempo dentro da média do padrão estipulado por lei para lançamento de efluentes em rios. Isso nos permite apontar que as agroindústrias de Araruna pesquisadas se adequam à legislação ambiental na gestão dos efluentes I e II, nos parâmetros analisados.

Nesse contexto, é importante ressaltar que há uma nítida diferença entre os resultados encontrados para os parâmetros analisados, haja vista as agroindústrias menores apresentarem para um nível tecnológico mais baixo e, conseqüentemente, maiores dificuldades em manter processos dentro do padrão em face do seu aporte tecnológico. As agroindústrias maiores, com aportes tecnológicos de última geração, conseguem maior rapidez, menores volumes de efluentes e cargas poluidoras menores, e conseqüentemente melhores resultados ambientais.

Tudo indica que a agroindústria II tem um controle maior da quantidade e qualidade de seus efluentes desde o processo até o momento em que lança os mesmos nas lagoas.

A agroindústria I, de menor porte, tem maiores dificuldades no controle dos parâmetros analisados, ou seja, em vários momentos da coleta, nas lagoas, ultrapassou os limites legais o que exigiu maior intervenção com custos no tratamento.

É válido lembrar que essa situação encontrada na região não é comum, ou seja, há situações muito diferentes em outras regiões do Paraná. Estudos apontam que as situações das farinheiras e do seu enquadramento a normas ambientais são extremamente problemáticas.

A Tabela 1 apresenta as tecnologias empregadas na secagem da farinha e a quantidade de Efluentes I e II gerados nas agroindústrias I e II.

As agroindústrias I utilizam para secagem da farinha forno a lenha, ou seja, o fogo direto no tacho com massa de mandioca, um processo antigo e artesanal, o que resulta em farinha grossa e de granulometria irregular. 
Nas agroindústrias II, o processo é mais moderno, pois, utilizam-se caldeiras para geração de vapor e o sistema de secagem é em tubos cilíndricos de movimento contínuo. Com isso, o rendimento, a eficiência e a uniformidade da secagem e do produto são maiores.

Quanto à geração de efluentes, pode-se verificar que parte dos empresários das agroindústrias I não conhece a quantidade de Efluente II gerado. O que se pode questionar aqui é como eles dimensionaram as lagoas de recepção do Efluente II, altamente tóxico? O que os leva a não se perguntarem e preocuparem com o seu volume, se a legislação é clara e a fiscalização é acirrada, na área de Campo Mourão?

O volume médio do Efluente Ié da ordem de 108.285 litros/dia. A média do Efluente II, das industrias que sabem, é de 9.000 litros/dia.

Quanto às agroindústrias II, verifica-se que os empresários conhecem a geração/dia de Efluentes I e II. A média é da ordem de 480.000 litros/dia de Efluente I e 28.000 litros/dia de Efluente II. O volume total médio trabalhado por ano das agroindústrias II chega ser 3,7 vezes maior do que o das agroindústrias I. agroindústrias II, pode-se inferir que podem estar trabalhando com um volume maior de matéria-prima.

Os meses em operação variam tanto na agroindústria I quanto na agroindústria II, conforme se observa na Tabela 2. Verifica-se que as agroindústrias I trabalham em média 7,4 meses e as agroindústrias II trabalham 10 meses.

O volume operacional médio por mês é da ordem de 702,86 toneladas para a agroindústria I e para as agroindústrias II é da ordem de 2.036,5 toneladas/mês. No entanto, as agroindústrias I ficam paradas um maior número de meses, o que indica poucos recursos monetários para comprar de fornecedores fora da região e/ou grande dependência dos fornecedores locais. As grandes empresas trabalham um maior número de meses por ano. Segundo pesquisa de campo isso ocorre porque estas empresas compram tanto dos fornecedores locais quanto externos por terem maior quantidade de capital financeiro para compra, industrialização e estocagem de produtos industrializados.

O fato de uma das agroindústrias de pequeno porte apresentar um volume de matéria-prima superior a

Tabela 1 - Secagem da Farinha e geração de Efluentes I e II - Agroindústrias I e II

\begin{tabular}{lccc}
\hline Empresas & Secagem da Farinheira & Efluente I & Efluente II \\
\hline Agroindústrias I & & & \\
\hline Aipin & Lenha - tacho & 40.000 & Não sabe \\
\hline Alinorte & Lenha - tacho & 150.000 & Não sabe \\
\hline Farinheira 31 & Lenha - tacho & 120.000 & 5.000 \\
\hline Farinheira Diamante & Lenha - tacho & 18.000 & Não sabe \\
\hline Mandionorte & Lenha - tacho & 40.000 & 8.000 \\
\hline O. R. Zeferino & Lenha - tacho & 60.000 & 15.000 \\
\hline Patrício & Lenha - tacho & 330.000 & 8.000 \\
\hline Agroindústrias II & & & \\
\hline Helce & Vapor - cilíndrico & 480.000 & 21.000 \\
\hline Pinduca & Vapor - cilíndrico & 480.000 & 35.000 \\
\hline
\end{tabular}

Fonte: Pesquisa de campo 2001

O maior problema é que as agroindústrias I usam, em média, por dia 108.285 litros para lavar cerca de 35,14 toneladas, o que equivale a 3,08 mil litros de água por tonelada de matéria-prima industrializada. As agroindústrias II, por sua vez, usam 480.000 litros/dia para lavar 101,82 toneladas, o que equivale a 4.750 litros de água por tonelada de matéria-prima (GODOY e SANTOS, 2003). O que se observa aqui é que os dois segmentos gastam muito mais água do que o permitido legalmente, que é de 2.000 a 2.500 litros/tonelada. No caso das uma empresa de grande porte (a Diamante, de pequeno porte, com 1.400 toneladas/mês e a Helce, de grande porte, com 883 toneladas/mês) necessita de uma explicação: a empresa de pequeno porte trabalhou dois turnos, durante 5 meses no ano de 2000. Durante o primeiro semestre do ano de 2001 ela não operou. A qualidade de seu produto é outro fator diferenciador: seu processo de secagem é em forno à lenha e o produto final é uma farinha branca grossa, comercializada em sacas de $50 \mathrm{~kg}$. 
Por outro lado, a empresa de maior porte e menor volume operacional trabalha com folga. Segundo seu gerente, opera durante 11 meses por ano, dos quais 4 meses em dois turnos. Possui forno de secagem contínua e produz produtos diferenciados como: farinha branca e farinha torrada, em pacotes de $0,5 \mathrm{~kg}$.
A Tabela 3 apresenta a Origem da Água, as horas de Captação por dia e a Capacidade Instalada das Empresas para a Captação de água.

Quanto às águas utilizadas no processamento da mandioca, verifica-se que nas agroindústrias I, a

Tabela 2 - Meses Trabalhados e Volume Operacional. Agroindústrias I E II

\begin{tabular}{lcccc}
\hline Empresas & $\begin{array}{c}\text { Meses } \\
\text { Operação/Ano }\end{array}$ & $\begin{array}{c}\text { Meses com } \\
\text { dois Turnos }\end{array}$ & ton/mês & $\begin{array}{c}\text { Toneladas/ano } \\
\text { safra 2000 }\end{array}$ \\
\hline Agroindústrias I & 11 & 5 & 450 & 5.050 \\
\hline Aipin & 10 & 3 & 200 & 2.000 \\
\hline Alinorte & 5 & 5 & 1.400 & 7.000 \\
\hline Diamante & 3 & - & 600 & 1.800 \\
\hline Farinheira 31 & 6 & 3 & 780 & 7.086 \\
\hline Mandionorte & 6 & 3 & 560 & 5.062 \\
\hline O. R. Zeferino & 11 & 3 & 930 & 8.400 \\
\hline Patrício & 7,4 & 3,7 & 702,86 & $5.199,71$ \\
\hline Valor médio & & & & \\
\hline Agroindústrias II & 11 & 4 & 383 & 9.713 \\
\hline Helce & 9 & 0 & 3.240 & 29.160 \\
\hline Pinduca & 10 & 2 & $2.036,50$ & $19.436,50$ \\
\hline Valor Médio & & & & \\
\hline
\end{tabular}

Fonte: Pesquisa de campo 2000/ 2001

O que se pode dizer é que as agroindústrias I, certamente, se adaptam à legislação, mas de maneira diferente das grandes agroindústrias. As industrias são mais artesanais e, com isso, enfrentam maiores dificuldades na manutenção dos parâmetros estabelecidos por lei e têm maiores custos. Seu sistema de lagoas é menos complexo que o das grandes indústrias, o que pode gerar, num período de alta produção, problemas ambientais. Soma-se a isso, o fato de industrializarem menores volumes de mandioca, de pouco valor agregado, e dependerem do fornecimento local.

Por outro lado, como não há um controle rigoroso por parte da fiscalização sobre a quantidade consumida de água, todas as agroindústrias ultrapassam o limite permitido pela lei.

No contexto apresentado, pode-se afirmar que, apesar das diferenças nos portes e tratamentos, observa-se que as agroindústrias I e II alcançam, com tecnologias diferentes resultados finais muito similares. maioria da água, $71,4 \%$, é captada em mina e $28,6 \%$ em poços. A quantidade captada em poço é bem superior à de mina. Três pequenas empresas se destacam (duas captam água de poço e uma que trabalha 12 horas e capta de mina) dado que somam 600.000 litros/dia. As 4 outras captam 58.000 litros/ por dia, há uma diferenciação grande entre as mesmas nessa variável.

Nas agroindústrias II, uma empresa capta água em poço e a outra capta diretamente do rio Guaritinga. As mesmas captam água por 8 horas todos os dias resultando em 960.000 litros/dia. De maneira geral, pode-se apontar que as horas de captação de água variam bastante. Na média, as pequenas agroindústrias captam água por 7,4 horas/dia, enquanto as maiores captam 8 horas por dia. A capacidade instalada difere bastante. A soma de todas as pequenas é inferior à somatória das duas agroindústrias grandes, embora ambas utilizem bastante água em seu processo produtivo. 
Tabela 3 - Origem , Capacidade Instalada e Horas de Captação da Água. Agroindústrias I E II

\begin{tabular}{lcccc}
\hline Empresa & Origem & $\begin{array}{c}\text { Capacidade } \\
\text { Instalada } \mathbf{~} \mathbf{h}\end{array}$ & $\begin{array}{c}\text { Hs de Captação/dia e } \\
\text { total/dia }\end{array}$ \\
\hline Agroindústrias I & & & & \\
\hline Aipin & Mina & 4.000 & 10 & 40.000 \\
\hline Alinorte & Poço & 30.000 & 5 & 150.000 \\
\hline Diamante & Mina & 1.500 & 12 & 18.000 \\
\hline Farinheira 31 & Mina & 10.000 & 12 & 120.000 \\
\hline Mandionorte & Mina & 5.000 & 8 & 40.000 \\
\hline O . R. Zeferino & Mina & 15.000 & 4 & 60.000 \\
\hline Patrício & Poço & 33.000 & 10 & 330.000 \\
\hline Sub-Total & & 98.500 & 61 & 658.000 \\
\hline Agroindústrias II & & & & \\
\hline Helce & Rio & 60.000 & 8 & 480.000 \\
\hline Pinduca & Poço & 60.000 & 8 & 480.000 \\
\hline Sub-Total & & 120.000 & 16 & 960.000 \\
\hline
\end{tabular}

FONTE: Pesquisa de campo 2000/ 2001.

OBS: $1 / \mathrm{h}=$ litros Por hora

Quanto ao destino dos resíduos agroindustriais, observa-se que a agroindústria I gera como resíduo casquinha, fiapos, pó de varreduras, aparas e cinzas enquanto as agroindústrias II são menos poluentes e geram casquinha e pó de varredura. Além disso, verifica-se nas agroindústrias I que $86 \%$ dos empresários acreditam estar destinando adequadamente os resíduos e apenas 1 empresário acredita que não está dando um destino adequado.

A destinação praticada aqui é de adubação do solo com a casquinha e Efluente II, e, em menor escala, a venda da casquinha para uso na alimentação do rebanho e venda de alguns resíduos tipo pó para outras empresas que os transformam em ração.

Nesse contexto, observa-se que a maioria dos empresários estão dando destino correto aos resíduos sólidos e líquidos gerados, principalmente Efluente II e casquinha. Segundo entrevistas com os mesmos, eles acreditam que tal preocupação melhora a imagem da empresa e o rendimento. Através da adubação das terras próprias ou de fornecedores é possível alcançar maior produtividade, garantir exploração futura e construir laços de amizade. Com o uso da casquinha para a alimentação animal há melhoras no faturamento através da integração pecuária e agroindústria e, mais, evitam-se multas futuras.

Os empresários das agroindústrias II, também, são unânimes em afirmar que estão dando um destino adequado aos resíduos agroindustriais. Essa adequa- ção para a agroindústria II passa pela integração da agroindústria com a pecuária por meio da irrigação de pastagem com o Efluente II, em menor escala, e, em maior escala, pela alimentação animal com a casquinha no cocho para o rebanho confinado.

Portanto, o que se verifica em todas as agroindústrias é uma eficiência no uso dos resíduos, e isso se traduz em ganhos adicionais. Para essas empresas, o que pode ser investido em melhorias do processo de produção é a busca por melhores aproveitamentos.

\section{Considerações finais}

Este trabalho objetivou averiguar se e como as agroindústrias da mandioca de diferentes portes se adequam à legislação ambiental.

Como resposta tem-se que ambas atendem à legislação ambiental. No entanto, os custos e o volume de resíduos a serem tratados pelas pequenas empresas são maiores do que os das grandes empresas.

Há um relativo consenso de que o atendimento às normas é um diferencial de lucratividade e, principalmente, para a pequena empresa uma maneira de se evitar multas.

A pequena empresa ultrapassou o limite legal em um maior numero de variáveis estudadas, mas por não ter tido condições de funcionar em sua capacidade máxima não chegou a poluir os rios. A questão que 
fica no ar é se ela conseguiria respeitar os limites se estivesse em toda a sua capacidade já que seus equipamentos são relativamente artesanais, o volume gerado de Efluente II é bem maior e seu produto tem baixo preço no mercado consumidor ou intermediário, por ter baixo valor agregado.

A grande empresa opera com tecnologia intensiva em capital e tem desde o inicio do processamento uma preocupação com os impactos ambientais já que este representa um diferencial no mercado interno e, principalmente, no mercado internacional. Seus produtos têm maior valor agregado e, conseqüentemente, maior preço no mercado. Com relação ao estudo somente uma vez ultrapassou o limite legal.

Pode-se apontar que as duas agroindústrias têm condições diferentes de tratar os seus resíduos líquidos e, seguramente, a empresa de menor porte tem maiores dificuldades no seu tratamento onerando, por mais uma via, necessária, o pequeno empresário.

\section{Referências}

ABAM - Associação Brasileira dos Produtores de Amido de Mandioca, Prefeitura municipal de Paranavaí, sindicato Rural, SEAB, EMATER, IAPAR, APROMAN - Plano para desenvolvimento $e$ modernização de produção de mandioca e derivados, apostila, 1999.

CEREDA, Marney Pascoli (Coord.). Resíduos da industrialização da mandioca no Brasil. São Paulo: Paulicéia, 1994.

CONCEIÇÃO, Antônio José da.- A mandioca. Cruz das Almas. UFB./EMBRAPA/PNB/BRASCON NORDESTE 1979.
FRANSON, Mary Ann H. - STANDARD METHODS for the examination of water and wastewater, $20^{\text {th }}$ edition, Baltimore, Maryland: United Books Press Inc., 1998.

GODOY, Amalia M. G e SANTOS, Ricardo J - A Agroindústria da Mandioca e o meio ambiente. Anais do VIII Seminário Modernização Tecnológica Periférica, Recife:PE, p. 1-17, de 12 a 14 de novembro de 2003.

RESOLUÇAO CONAMA No 20 - Classifica, segundo os seus usos preponderantes, as águas doces, salobras e salinas do Território Nacional, 18/06/1986.

SEMA/IAP - Secretaria do Estado do Meio ambiente e Recursos Hídricos e Instituto Ambiental do Paraná Decreto Estadual 857/79. In: Manual de Licenciamento Ambiental, 1998a.

SEMA/IAP - Secretaria do Estado do Meio ambiente e Recursos Hídricos e Instituto Ambiental do Paraná - Lei Estadual 7109/79. In: Manual de Licenciamento Ambiental, 1998b.

SPERLING, Marcos von. Introdução à qualidade das águas e ao tratamento de esgoto. 2. ed. rev. Belo Horizonte: UFMG. Departamento de Engenharia Sanitária e Ambiental, (Princípios do tratamento biológico de águas residuárias ; v.1). 1996.

TERRA ENGENHARIA AMBIENTAL: Consultoria \& Projetos. Projeto Básico de Sistema para Tratamento de Efluentes. Farinheira 31 Ind. \& Com. Ltda, Araruna-Pr.; fev. 1997.

Submetido em maio/2002 Aprovado em julho/2004 